\title{
An Infographic Approach to Presenting Dance Data from the Choreographer's Studio
}

\section{Cover Page Footnote}

This work was supported by the ERC (European Research Council) under the project 'BlackBox: A collaborative platform to document performance composition: from conceptual structures in the backstage to customizable visualizations in the front-end' (Grant Agreement ref. 336200). We extend our acknowledgments to João Fiadeiro and the dancers who have participated in this case study, as well as to the team at Re.Al for their technical support and collaboration. We also extend our acknowledgments to Rui Lopes Graça, Joao Penalva and the CNB (Companhia Nacional de Bailado) who have hosted the second case study. 


\section{Introduction}

The authors of this paper have been developing an infographic approach for the presentation of dance data in the framework of the BlackBox - Arts \& Cognition Project (2014-2019), ${ }^{1}$ a long-term research project funded by the ERC. At the time of writing this paper, the infographic approach was implemented in $2 \mathrm{D}$ and $3 \mathrm{D}$ multimedia environments, resulting in the creation of four short animated infographic films, a documentary film, and a multiple viewport platform for two 360-degree dance videos. These infographic film productions introduce the viewer to the creative processes and production of new stage works by two very different Portuguese choreographers: João Fiadeiro (known in Europe for his Composition in Real Time method), and Rui Lopes Graça (resident choreographer at the National Ballet Company).

All infographic film productions are available from the BlackBox - Arts \& Cognition website and were produced for dance professionals (academics, artists, performers, students, and others) and for the interested non-specialist audience. At first glance, these infographic films seem to be straightforward examples of scientific information visualization, as they present the research findings of the respective BlackBox case studies to a secondary audience in a comprehensible way. While this is entirely the case, the BlackBox infographic film productions do also challenge existing notions of what constitutes "dance data" and how these can be collected, processed, interpreted, represented and visualized. More concretely speaking, the authors will present two distinct case studies in this paper, which discuss entirely different sets of "dance data" and require specific visualization strategies to access each choreographer's unique artistic vision and creative process.

Each infographic film production is as much an example of scientific information visualization as it constitutes an act of media-practice-as-research. Research design and methodologies developed in the BlackBox case studies are rooted in the social sciences. Qualitative and quantitative results of the research on the choreographers' creative processes and on the compositional and dramaturgical structures of the dance productions are validated and prepared for visualization. It is at this stage that the infographic approach initiates an additional media-practice-asresearch cycle. Information visualization is different from plain data visualization in that a journalistic approach is employed to create a comprehensive narrative about the processed data sets and findings. The core of the infographic approach presented in this paper is the use of "embodied filmmaking" techniques, which allow the viewer to 
engage with scientific data, information, and knowledge through kinaesthetic empathy. A good example for "embodied filmmaking" techniques are the various modalities in 360-degree video environments that a viewer can choose from to appreciate the infographic films about Rui Lopes Graça's work, which are presented and discussed in the second case study. Before the authors venture into the case studies and detailed discussion of the infographic approach, it is helpful to clarify existing notions and uses of the term "dance data."

\section{What is "Dance Data"?}

The term "dance data" in computer science literature is synonymous with dance movement data, or motion capture data. More often than not in this context, the idea of "dance" is that of one or more human bodies which are moving in a carefully composed fashion in time and space. Consequently, movement is considered the quintessential characteristic of dance that needs to be captured and preserved for documentation and transmission. Moreover, computing movement in practice means automated computing of selected attributes of movement (more on this anon). While this understanding of "dance data" may be arguably sufficient in one scientific area (computer science), in other academic fields such a generalist notion of dance is considered overly reductionistic. In the field of performance studies, for example, dance is studied as a cultural practice. From this much broader perspective, "dance data" includes aspects of dance beyond the simple performance of movement: conception, creation, performance, documentation, reception, teaching, analysis, research, production, marketing, and so forth. In-between such epistemological and methodological extremes, it is helpful to take a closer look at prominent dance archive projects and examine what kind of "dance data" they consider, collect, and offer with regard to a particular choreographer or work.

In a 2017 article for Computational Culture entitled "Dance Becoming Data," Scott deLahunta writes in a section subtitled "Everything is Data" about the workflow of capturing, processing, analysing, and presenting data obtained from the creative processes of choreographers who were collaborating in the framework of the Motion Bank project. ${ }^{2}$ Here, "dance data" encompasses video and audio recordings, motion capture data, scores, manual annotations, processed video material, visualizations, and other representations of connections built by researchers and artists through a combination of computational and manual work. The focus of Motion Bank was the development of online scores. In Deborah Hay's scores, for instance, the team worked 
from three main directions: one direction was analytic, based on data collected from as many performance recordings as possible; another was intuitive, an artistic response to what was learned about Hay's process; and the third direction was based on interviews focused on concepts and insights. ${ }^{3}$ It is therefore clear that their concept of "score" was understood in a rather broad perspective, covering different kinds of "dance data."

Motion Bank was inspired by its precursory project Synchronous Objects For One Flat Thing, Reproduced. ${ }^{4}$ Researchers Norah Zuniga Shaw and Maria Palazzi, with choreographer William Forsythe, describe in their article "The Dance, The Data, The Objects" how two types of data sets were obtained: "s "spatial data" extracted from the source video of the dance by means of motion tracking techniques, and "attribute data" obtained from the dancer's reports. The "attribute data" served as metadata, cataloguing the information provided by the dancers in three categories (movement material, cues, and alignment). These categories correspond to three systems of organization of the dance, or three central elements of Forsythe's choreographic thinking with regard to One Flat Thing, Reproduced.

Driven by Sarah Whatley at Coventry University, the digital dance archive of Siobhan Davies had the aim of bringing together all of the materials and documentation associated with Davies' choreographies into a single collection. It provides online access to multimedia content (video, text, audio, image) as well as a comprehensive collection of material that documents the creative dance-making process. ${ }^{6}$ The archive is designed to invite new ways to explore the content and provides tools to create new kinds of digital objects. The metadata she used to organize the archive was an expanded version of Dublin core, adapted to the particularity of dance content. "Replay" also has a virtual scrapbook, allowing users to collect, analyse, and reconstruct their searches. This is a novel example of the diversified ways of reusing archived dance data, as it not only honors Davies' past work but also contributes to a new form of creative output.

Whatley has also reflected on the concept of "accidental archives," which she defines as "curated libraries of valuable performance documents."7 Those archives often emerge from documents used for dance training purposes, which gradually and without a previous intention, become a relevant repository of performance documents and related materials such as personal diaries or notebooks. In those "accidental archives" there is a shift from the documentation of the finished and staged performances to the documenting of the training process in itself (in various forms and formats). 
Cognitive linguist Carla Fernandes has developed a different approach to dance data collection, classification, interpretation, and visualization through her TKB (Transmedia Knowledge Base) and BlackBox Arts \& Cognition projects. ${ }^{8}$ Fernandes and her team(s) have been exploring multimodal video annotation as an interdisciplinary methodology, drawing on cognitive linguistics, multimodal communication, performance studies, computer sciences, and more recently, cognitive neurosciences. The TKB project has produced two supporting tools for artistic and academic communities: a multimodal video annotation software called the "Creation Tool" and the TKB online archival platform, a transmedia knowledge-base open to artists, researchers, and other professionals interested in registering and contributing to what Fernandes calls "an archive of processes." Unlike other existing video annotation software, the "Creation Tool" functions like a digital notebook, allowing the capture of video streams simultaneously with annotations of various types being added either in real time or in post-production. Still in the framework of the TKB project, multimodal video annotation methods have been conceived, implemented and carried out in an extensive case study on signature works of the choreographer Rui Horta, which can be visualized on the TKB platform. ${ }^{9}$ Currently, the BlackBox project team is further developing and refining multimodal video annotation methods and case study specific new forms of visualization of source data and processed data. Multimodal video annotation methods require the elaboration of a custom-designed annotation scheme in preparation for the annotation process. Hence the annotation scheme reflects the annotator's approach to classifying the data and to organizing central choreographic concepts and strategies into respective categories. ${ }^{10}$

To sum up these references to major movement research and dance archive projects, the term "dance data" is currently used as an umbrella term, and has not yet been unambiguously defined. Looking at the aforementioned examples, it is evident that only a much broader understanding of "dance data" allows the researcher to grapple with the intrinsic complexities of today's contemporary dance practice and creation. In consequence, the authors have designed the differing case studies presented in this paper with the following research question in mind: Which aspects of contemporary dance and choreographic thinking can be computed and visualized in a way that allows access to each choreographer's unique artistic vision and creative process? In the following section of the paper, the authors will answer this question from two very distinct perspectives, and discuss their infographic approach to representing dance data from the choreographic studios of João Fiadeiro and Rui Lopes Graça. 


\section{What are Animated Infographic Films?}

Scientific visualizations are commonly associated with data visualization as a field of descriptive statistics, where quantitative data are coded and represented. In contrast, information visualizations generally introduce some form of analysis of the presented data and frequently include other graphical elements that do not derive from data representation.

According to Ma et al. (2012) "difficulties arise when introducing scientific visualizations to broader audiences. Even the best visualizations are incomprehensible if their concepts are alien, and scientific visualizations often assume viewer familiarity with the subject matter." 11 To address these difficulties, our infographic approach to representing dance data provides access to complex compositional concepts through the implementation of what we have elsewhere called "embodied filmmaking."12 This approach is based on insights from embodied cognition theory, and in practice results in the attempt to digitally recreate aspects of the choreographer's studio. Gaining access to specific periods of the creative process is of interest for both the professional artistic and academic communities, as well as a broader audience. Accordingly, our infographic approach to the representation of dance data will display precise research data and results through the use of data visualization techniques, and additionally create a narrative context through infographic tools and embodied filmmaking techniques, which serve to deepen the audience's understanding of the presented content.

However, infographic storytelling in the digital realm can take place in different interaction design environments and thus further enrich the user experience. Ma et al. refer to Wohlfart and Hauser, who have proposed a taxonomy of four modes for splitting control between the author and consumer by varying degrees: passive storytelling, storytelling with interactive approval, semi-interactive storytelling and total separation from the story. ${ }^{13}$

In our animated infographic films, documentary films with infographics, and 360-degree video productions with infographic layers, we have worked within three of Wohlfart and Hauser's modes for splitting control in order to explore different avenues for the representation of dance data. The two case studies presented below will discuss some of the advantages and limitations of these different modes of interactive visualizations. 


\section{Case Study 1: João Fiadeiro}

In an earlier article for the PARtake journal, we have presented and discussed animated films produced by the BlackBox Arts \& Cognition project on selected solo works of Portuguese choreographer João Fiadeiro. ${ }^{14}$ This article introduced two main strategies of our embodied filmmaking approach:

(1) the ubiquitous spectator, present in the camera perspective and animations as the dynamic viewpoint; and (2) the physical materialization of highly abstract and complex concepts as two- and three-dimensional graphic models and elements. By inviting the viewer of the film to enter the digitally re-constructed studio space, we provide the sensation of being kinesthetically transported to the conceptual, and imaginative space of João Fiadeiro's artistic universe. ${ }^{15}$

The concept of the ubiquitous spectator of the animated infographic film describes a dynamic viewpoint from a first-person perspective, which invites the viewer of the film to engage with the presented dance data as if s/he was the researcher entering Fiadeiro's studio to observe a workshop or rehearsal. This dynamic viewpoint is supported and augmented by the introduction of digitally re-constructed graphic models, which can be kinesthetically experienced as physical objects in the studio space.

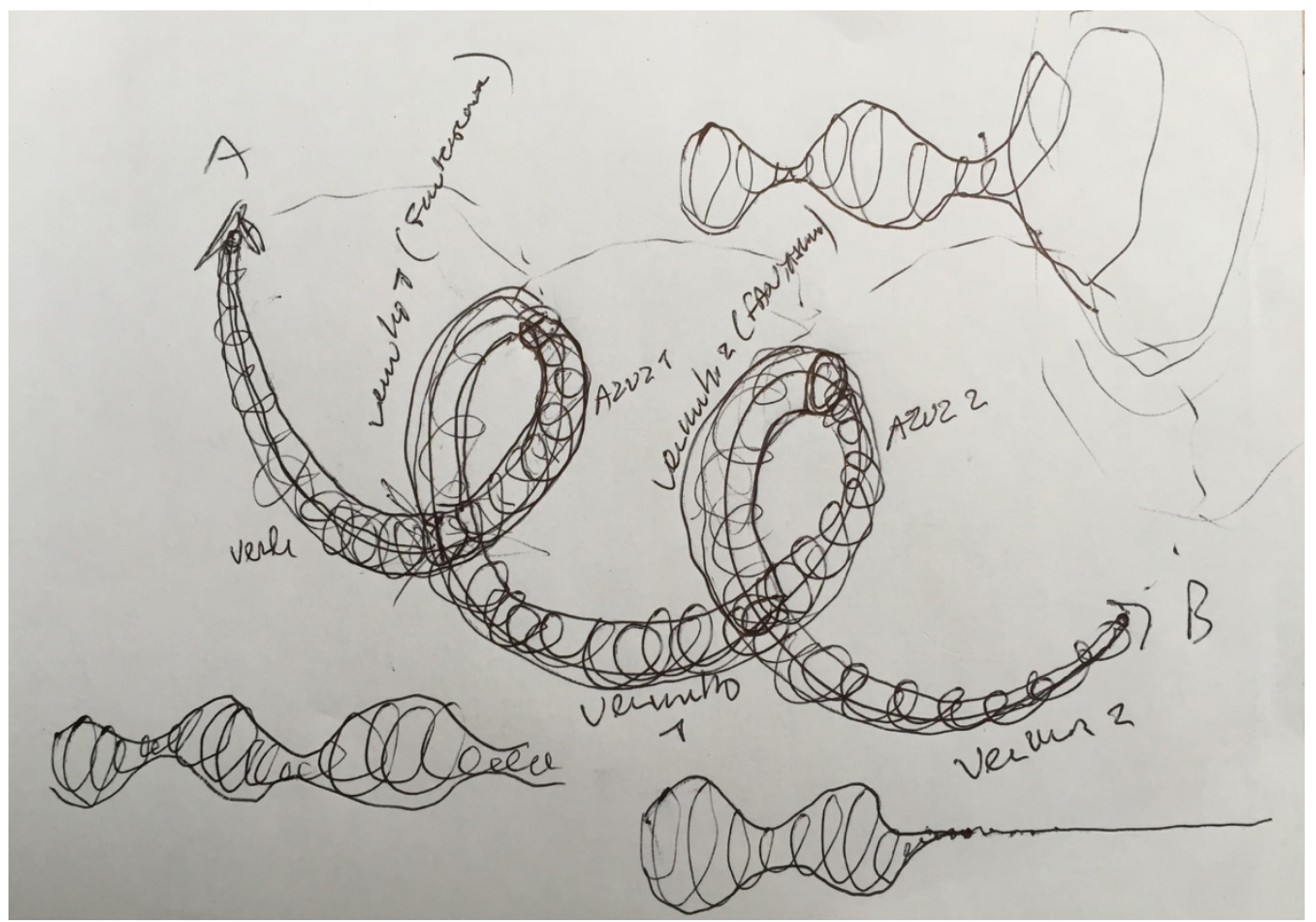

Figure 1. Drawings by João Fiadeiro during an interview session with Stephan Jürgens, created to explain different improvisational dynamics. 


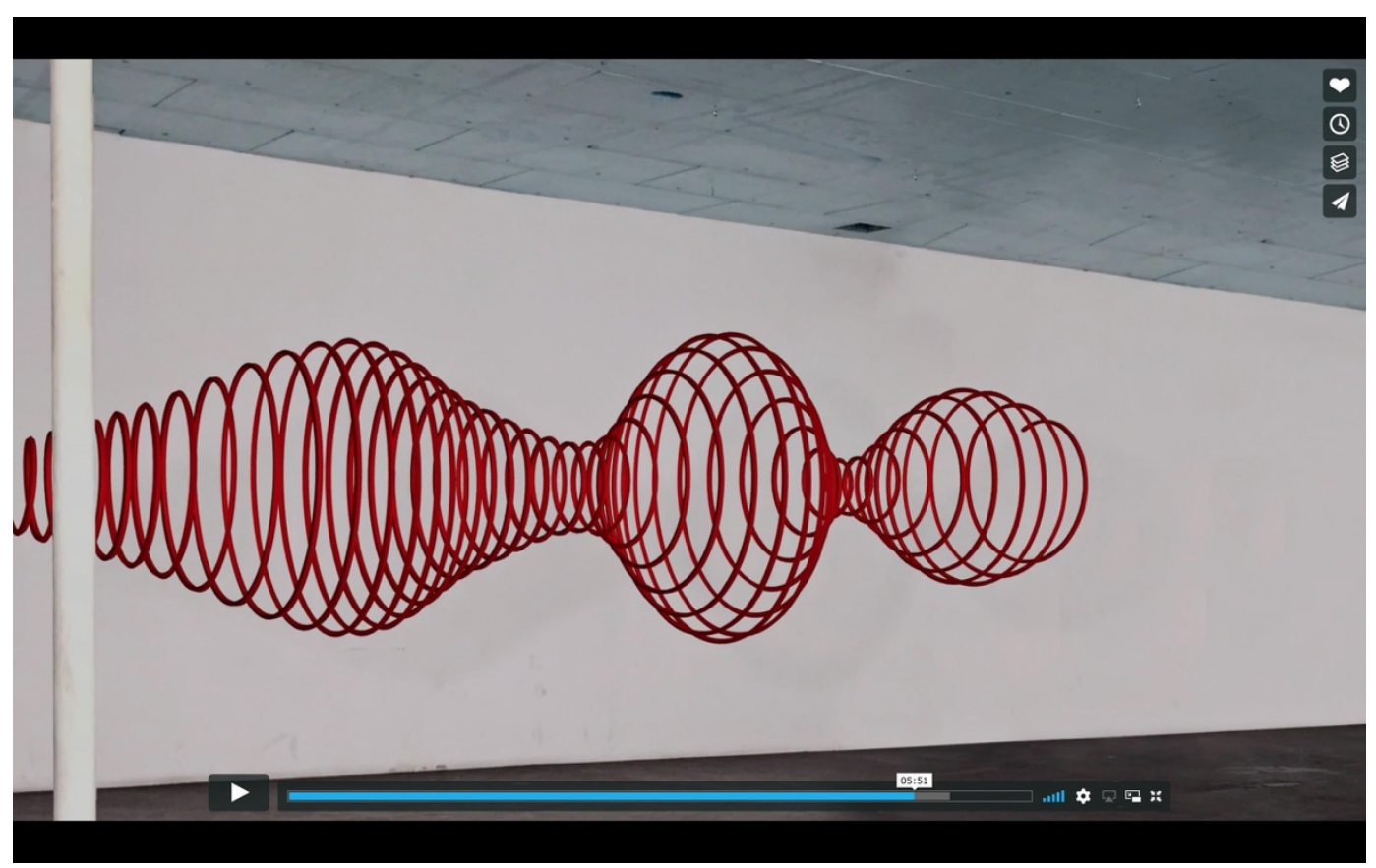

Figure 2. Video still showing a 3D graphic model of an improvisational process over time, recreated from the drawings by João Fiadeiro (displayed in Figure 1).

Figures 1 and 2 show, respectively, how we re-constructed Fiadeiro's “worm model" (a visualization of different dynamics in improvisation), based on his drawings. ${ }^{16}$ All four animated infographic films produced by the BlackBox project on selected solo works by Fiadeiro are available online. ${ }^{17}$ These films fit into media theorists Wohlfart and Hauser's first mode of splitting control between viewer and author (passive storytelling). ${ }^{18}$ It can be argued, however, that through providing additional information (or dance data), such as text excerpts from Fiadeiro's program notes, links to articles about the films and links to archival material provided by Fiadeiro, the viewer of the films can choose to consult complementary content. Hence the available research information is presented in an overlapping form combining Wohlfart and Hauser's first (passive storytelling) and second (storytelling with interactive approval) modes of interaction with the contents.

The documentary film about the creative process of João Fiadeiro's group piece O Que Fazer Daqui Para Trás (What to do with what remains) naturally falls into the passive storytelling category. Nevertheless, the film represents and visualizes dance data and research findings in an unconventional way: we selected primary and secondary dance data, ${ }^{19}$ organized the video footage, photographs, drawings, web references and texts based on the four stages of Fiadeiro's creative collaborative 
process, and employed our infographic approach to visualize complex concepts and the dramaturgical structure of the stage work..$^{20}$

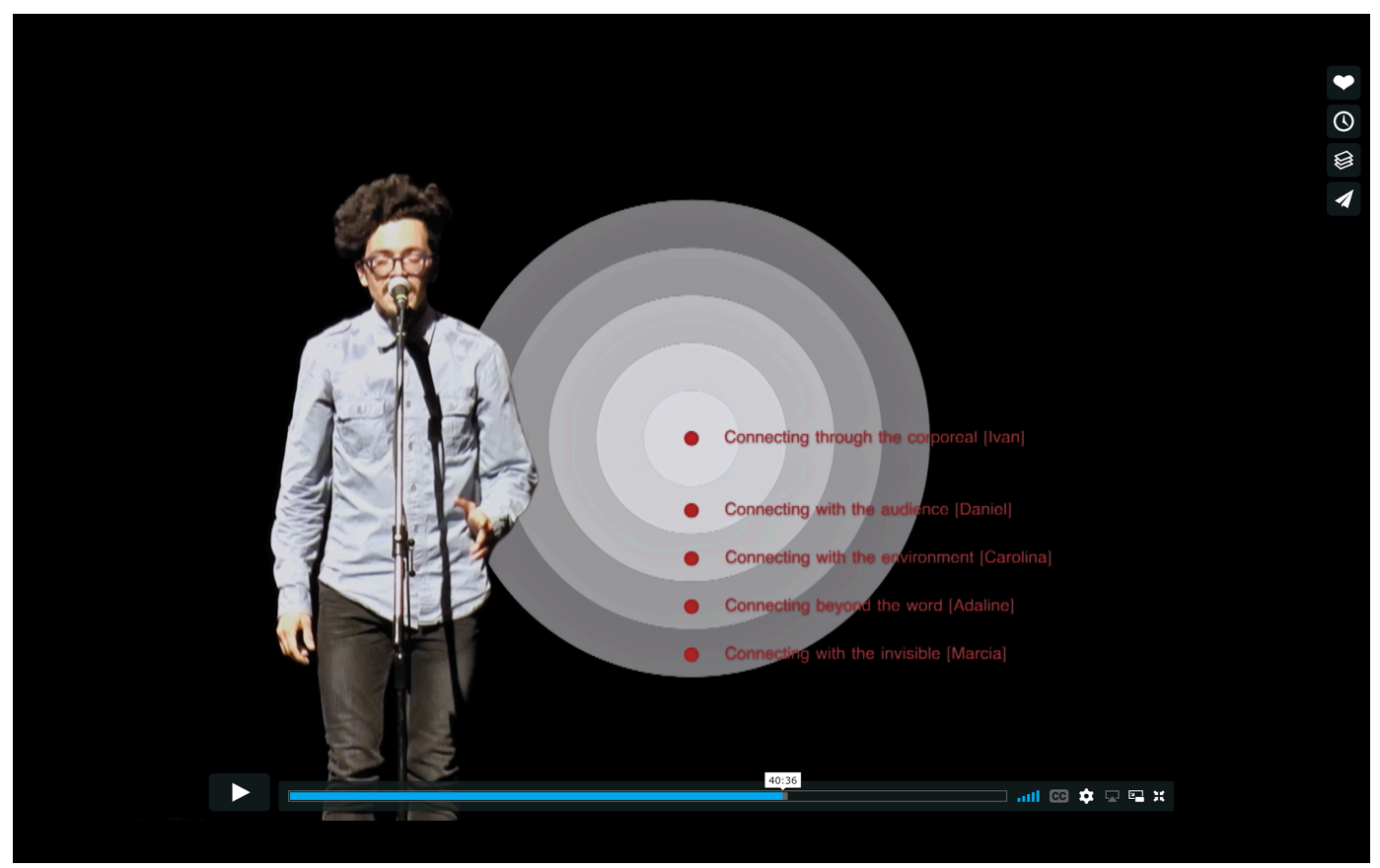

Figure 3. This video still from the documentary film displays an animated disk model, based on a drawing which João Fiadeiro used to organize the discourses delivered by each of the five performers during the piece.

In O Que Fazer Daqui Para Trás, five performers run, for the entire length of the piece, in the surroundings of the theatre venue, and drive themselves into a state of physical and mental exhaustion. Each time they pass through the theatre, they stop center stage in front of a microphone and share their experience with the audience. Figure three shows how Fiadeiro organized the different discourse dimensions in collaboration with the performers. While one performer would report what just happened to the body, another dancer shared impressions from the immediate surroundings of the theatre, yet another dancer addressed the audience directly to engage in reflections upon their relation, and so forth. ${ }^{21}$ Fiadeiro used the drawing a disk model to clarify and separate the different discourse dimensions in collaboration with his performers, who consecutively developed their improvised yet structured texts. We recreated the disk model by means of an animated infographic and combined this motion graphic with an animated timeline of the dramaturgical structure of the piece.

In the second animated infographic, the five discourse dimensions are laid out horizontally and show the entrances, exits and the time of the shared discourse performed by each dancer (see figure 4). This animation also visualizes how the pauses between each event on stage diminish with the increasing exhaustion of the performers: 
towards the end of the piece, the dancers enter the stage much more frequently, and finally, the piece comes to an end, when one of the dancers can't run any further.

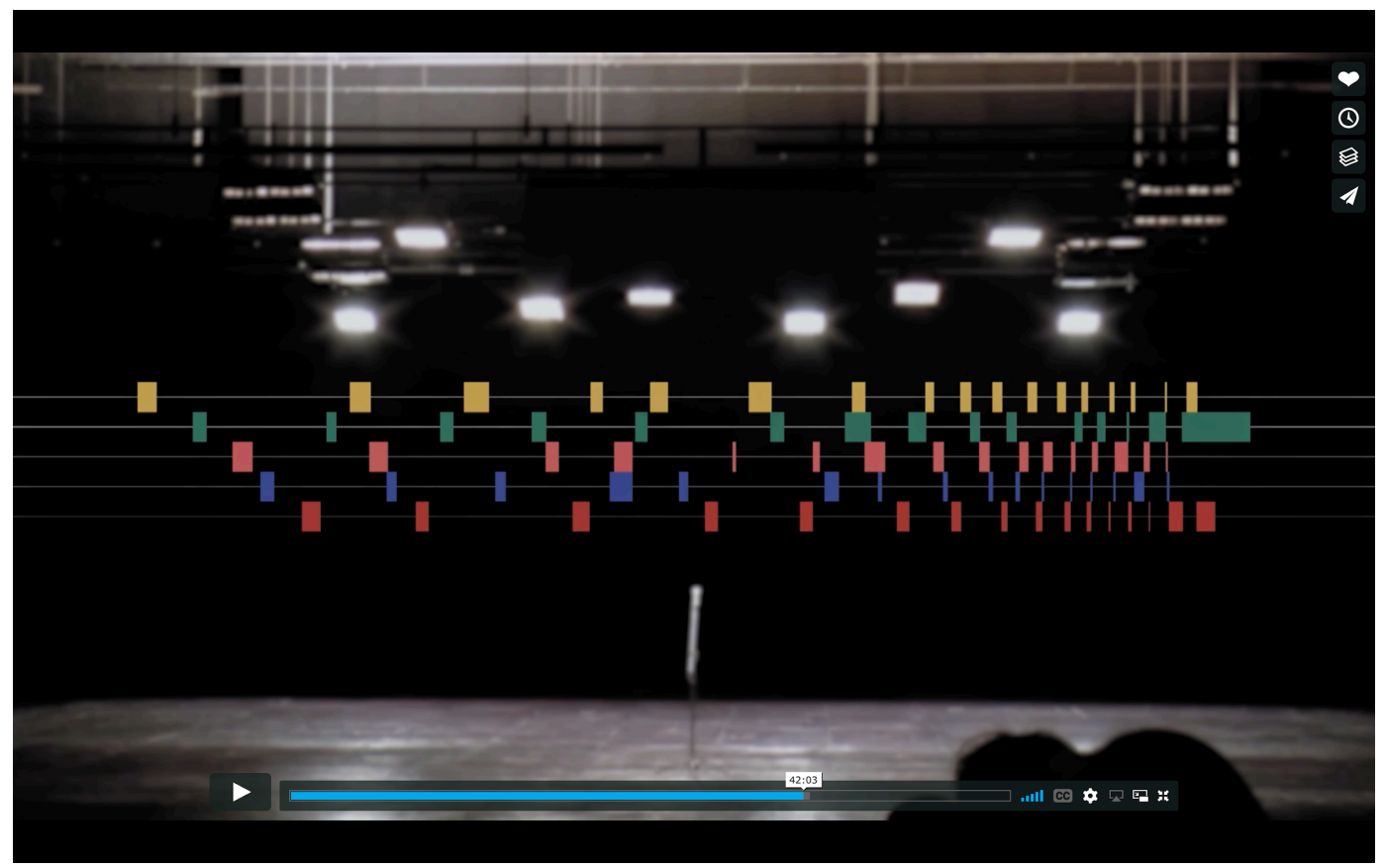

Figure 4. Video still of the animated timeline, along which entrances and exits of the dancers are visualized.

\section{How to Compute Concept Dance: Some Critical Thoughts on What Constitute "Dance Data" in the João Fiadeiro Case Study}

Throughout the past decades, contemporary art practice has increasingly included conceptual and self-reflexive dimensions in creation processes and the making of the final artwork. In contemporary dance, all kind of information (personal biographies, artistic research data, references to the production context and so forth) can be integrated as compositional material and dramaturgical strategy. ${ }^{22}$ João Fiadeiro's work can be best described as "self-reflexive post-modern dance" and as "concept dance." ${ }^{23}$ To describe and interpret artistic practice in these forms of contemporary dance accurately, a researcher evidently has to go beyond common notions of dance such as dance being an (artistic) activity where one or more human bodies are moving in a carefully composed fashion in time and space. Consequently, if the movement performed by the dancer(s) is not the essential component of the dance work under scrutiny, then what other dimensions of the creative process and the performance need to be looked at? If it is not primarily the dancer's movement that needs to be (motion) captured for documentation and analysis, what does one record and compute? In other words, and to rephrase the authors' research question presented 
above: Which aspects of Fiadeiro's choreographic thinking can be computed and visualized in a way that allows access to his unique artistic vision and creative process?

To answer this question, it is helpful to refer to dictionary definitions of the term "computing." As a transitive verb (used with an object), "to compute" is generally defined as "to make a calculation" (Merriam-Webster) or "to reckon or calculate" (Oxford). In this sense of the term, we need dance data that can be quantified and calculated. When used as an intransient verb (used without a direct object) "to compute" is defined as "to use a computer" (Merriam Webster). Or, as the Techopedia dictionary (by Northwestern University) states:

Computing is the process of using computer technology to complete a given goal-oriented task. Computing may encompass the design and development of software and hardware systems for a broad range of purposes - often structuring, processing and managing any kind of information-to aid in the pursuit of scientific studies, making intelligent systems, and creating and using different media for entertainment and communication. ${ }^{24}$

For our purposes, we use the term "to compute" in the latter sense, and do so at all stages of our scientific research and dissemination. This approach allowed us during the course of the case study on João Fiadeiro's work to avoid limiting ourselves to considering only dance movement data sets; it also allowed us to explore conceptual, compositional and dramaturgical dance data sets. To this end, we employed recent computer technologies available to the researcher today:

1. Digital image and sound processing technologies (for pattern recognition analysis, motion tracking, post production and other purposes).

2. Combinations of hand-coding (multimodal video annotation methods) and automated data processing techniques.

3. Digital reconstruction and information visualization techniques (for inclusion and processing of abstract and conceptual compositional elements)

If, as Scott deLahunta affirmed, "everything is data," and if these (dance) data are available in a digital format, then there is virtually no aspect of contemporary dance and choreographic thinking, which cannot eventually be computed and visualized.

Throughout all BlackBox film productions (the four animated films and the documentary) the authors have developed their approach to the representation of dance data through embodied filmmaking and animated infographic techniques in a $2 \mathrm{D}$ environment. The second case study was carried out in a very different setting in collaboration with the Portuguese National Ballet Company. Towards the end of the production process of a neoclassical ballet piece, two selected scenes of the ballet were 
filmed in both traditional frontal video and in 360-degree video formats, in order to build a 3D platform for the exploration of the dance and underlying compositional concepts. The following section of the paper gives a rundown of the development of our 360-degree dance video platform and the implementation of the infographic approach in a $3 \mathrm{D}$-environment.

\section{Developing a Multiple Viewport Platform for 360-degree Dance Video}

In scientific information visualization such as our infographic film productions, academic research processes and dissemination production can employ artistic methods, particularly in interdisciplinary art and science collaborations. Here, media artists especially "function as augmenters of research, enhancing the representation, interaction, tool-building or narrative components of the research in order to make it more effective for domain-experts and more accessible to outsiders. ${ }^{25}$ In the field of performance studies, some art and science projects have produced choreographic objects, which are "not the same as the performance to which it relates. Choreographic objects attempt to provide a layer of analysis through an abstraction from the dances. They (...) disseminate dance knowledge across a wide community." 26 Taking on the form of online graphic scores, navigable video content, or interactive multimedia installations (amongst other possibilities), such choreographic objects let the user partake in "thinking about choreographic thinking." ${ }^{27}$ In the case of the multiple viewport platform for 360-degree dance videos presented in this paper, a combination of media technologies (omnidirectional video, animated infographics and interactive interface design) has been implemented to visualize certain compositional structures of a contemporary ballet as the user is watching the recorded dance performance. Moreover, since analytical knowledge in dance cannot be dissociated from the somatic experience of this art form, a design approach informed by the field of embodied cognition was adopted. In other words, the platform was developed to be explored across different viewports (computer and connected screens or projectors; mobile devices and Virtual Reality headsets) and to allow the user to physically relate to the content in different ways. Instead of presenting a single "optimized" interface for the transmission of research results, the platform is conceived from a media practice-asresearch perspective to raise further epistemological questions: What can I learn about the dance in the immersive omnidirectional view? What will I be missing? Which advantages does another viewport provide watching the same section of the dance? 
How does one form of viewing complement another and add to my understanding of the composition?

Our research of 360-degree video featuring classical and contemporary ballets (mainly through the YouTube, Vimeo and Facebook platforms) has shown three different approaches to filmmaking: documentary-style excerpts of ballet productions, ${ }^{28}$ transposition of a ballet (or excerpts thereof) into a custom-designed VR environment, ${ }^{29}$ and short duration ballet productions choreographed exclusively for the 360-degree video format. ${ }^{30}$ While our own 360 -degree ballet videos can be categorized as "documentary-style," the animated infographic layers add an analytical dimension to these films. Embedded in the online platform we have created, they are more precisely classified as "360-degree infographic dance films" and hence represent a new form of choreographic object.

Information visualization techniques have been employed in some of these hybrid art and science objects to facilitate access to choreographic thinking, conceptual structures and compositional strategies. ${ }^{31}$ Alternatively, some choreographic objects have been designed from an embodied cognition approach ${ }^{32}$ to engage users physically with complex and abstract concepts as well as with principles that need to be experienced somatically. Media practice in interdisciplinary collaborations aimed at the creation of choreographic objects can benefit from an embodied cognition approach and lead to the production of unique and novel formats, as the authors have discussed above, suggesting the notion of "embodied filmmaking" in the context of animated infographic (dance) films. ${ }^{33}$

Case studies on scientific visualization in 3D environments discuss pros and cons of 360-degree viewing and suggest for example the integration of an annotation system to provide additional information ${ }^{34}$ and/or the implementation of the semiinteractive storytelling approach to make complex data and patterns accessible to the user mentioned above. ${ }^{35}$ These important visualization principles have informed the iterative design ideas and implementation of our own platform.

\section{Case Study 2: João Penalva and Rui Lopes Graça}

João Penalva (director, stage and costume design) and Rui Lopes Graça (choreography) are the authors of the contemporary ballet Fifteen Dancers and Uncertain Time (2016) presented on the 360-degree dance video platform. ${ }^{36}$ The piece is conceived as a "white ballet," in which the different strands of the performance (choreography, sound ambience, stage design and lights) are co-existing in a non- 
narrative composition. Challenging the tendency to look for a narrative in a ballet, the authors of the ballet invite their audience instead to let their own imagination take part in the creative process of meaning-making. To this end Penalva and Graça adopted an "algorithmic" or rule-based compositional approach, which eventually took the form of a list of guiding principles of what the dancers could explore and what they needed to avoid. For the platform we have selected two sections of the ballet which particularly lent themselves to visualizing the salient compositional principles, and thus to accessing and experiencing aspects of the authors" "choreographic thinking" first-hand.

The selected sections (twelve and sixteen) were filmed with a $4 \mathrm{~K}$ two camera 360-degree system from a single viewpoint perspective located center stage. Additionally, both sections were filmed from the auditorium (Full HD recording). Dance data sets were obtained through multimodal video annotation, which served for coding the infographic visualization layers added to the films. As a result of subsequent interface design iterations, the platform in its present form offers both, an "audience view" and a "stage view" mode. Activating the "audience view" mode, the user is presented with the $2 \mathrm{D}$ video filming in a $180^{\circ}$ environment, which emulates the spectator's experience in a theatre auditorium (for example, the distance to the stage and the angle of the frontal perspective can be explored). In "stage view' mode, the user experiences an immersive $360^{\circ}$ environment (as if standing in the center of the stage amongst the dancers).

Section 12 of the ballet (called the Adagio section) starts with a four-minute long solo danced by Andreia Mota. Subsequently, the remaining fourteen dancers enter the stage successively. Each dancer performs exactly the same choreography, composed of four sections. In other words, the Adagio section is formally constructed as a canon (a musical form where the same music is performed at different times by several voices). However, each dancer visually cues off another dancer (instead of using musical references) and performs the choreography in their own time.

Originally, the dancers were spatially organized along two diagonals. Throughout the rehearsal period, the choreographer adjusted the starting positions of the canon material according to the evolving composition: some dancers started close to the original position, and others commenced in a different area of the stage. We have visualized these compositional principles graphically (in the "stage view" mode). As soon as a dancer arrives at the position onstage where s/he will start to perform the canon, his or her name will appear in the space overhead, together with a colored bar and a playhead, which indicate the part of the canon that is danced at the present time. 
In the space below the dancer, an animated graphic appears and displays the deviation from the original position assigned to the dancer on the respective diagonal (see figure $5)$.

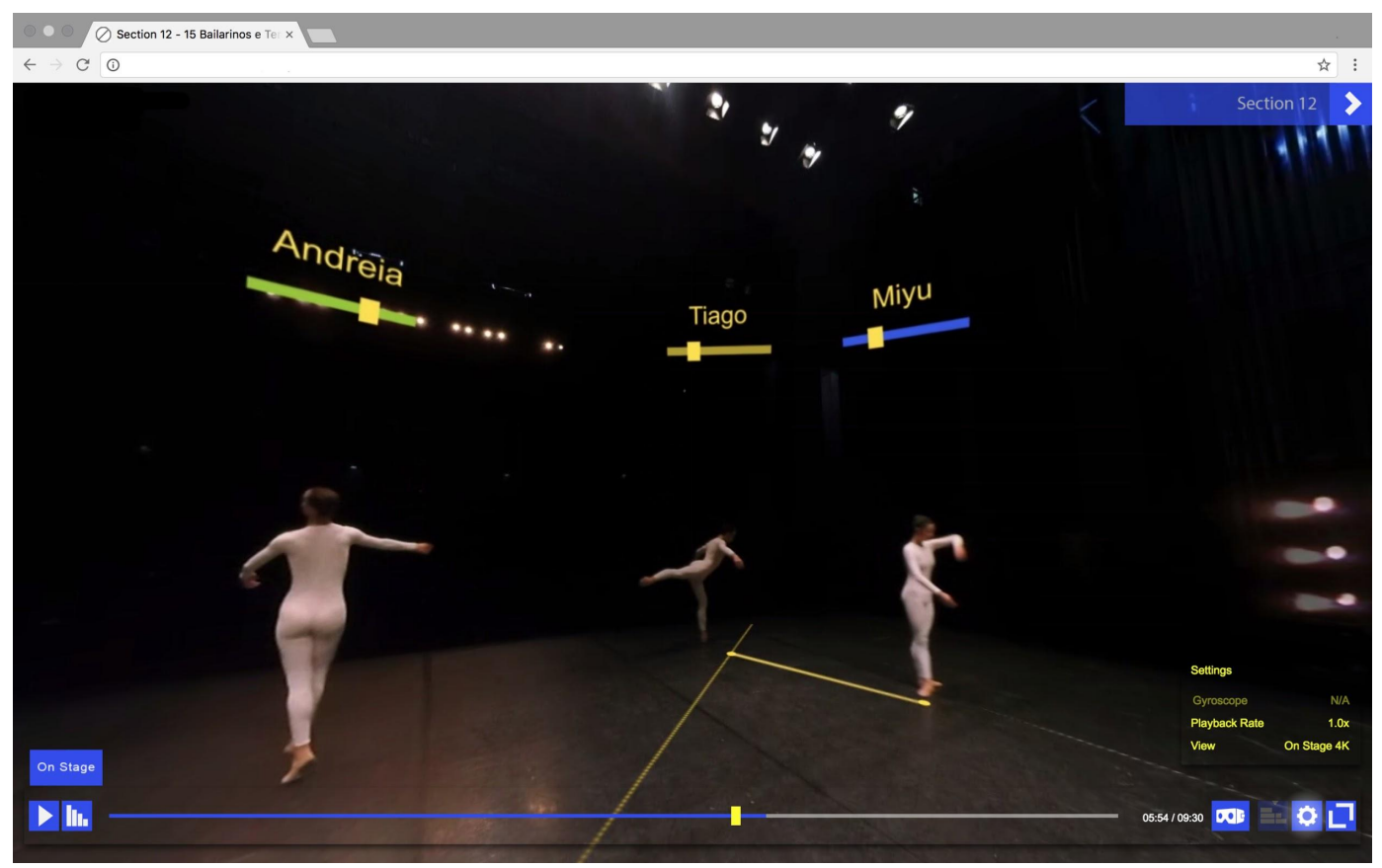

Figure 5. Screenshot of section twelve in stage view mode.

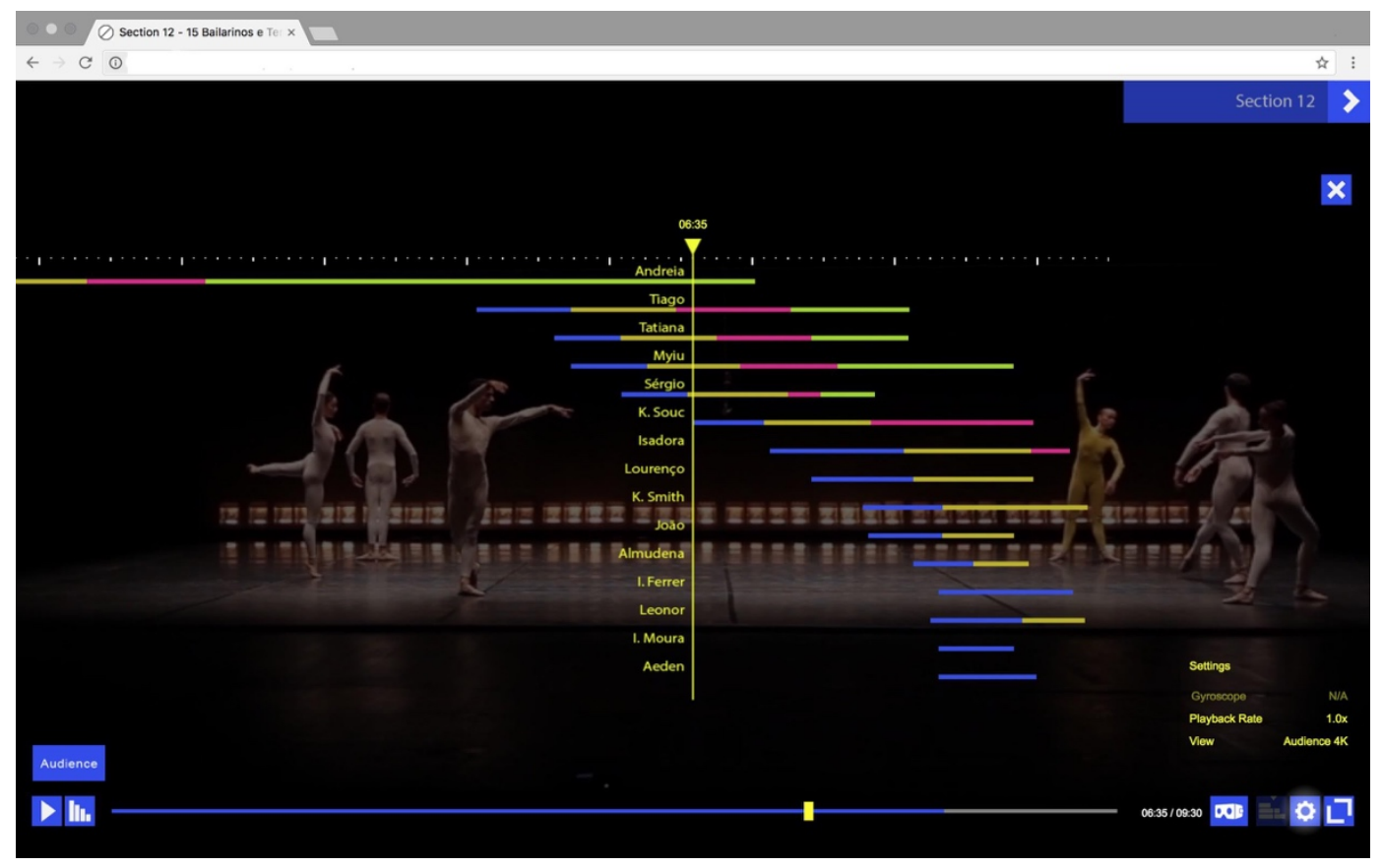

Figure 6. Screenshot of section twelve in audience view mode with activated graphic score.

In the audience view mode, the platform user can watch the Adagio section from the frontal perspective. Additionally, a graphic score can be activated by clicking the designated button (see figure 6). The interactive score lists all dancers in the order of 
their entries on stage and allows to jump to the respective section in the video. This feature of the platform interface is particularly useful if the user wants to identify an individual performer through switching to the stage view mode and follow this dancer while receiving the information described above.

The second infographic 360-degree film presents section 16 (called the Rewind section) of the ballet. In this final part of the piece, the dancers perform the ballet "backwards," starting with the last section (fifteen) and ending with section one. Moreover, some dancers perform movement sequences in a reverse mode and thus create a counterpoint to their colleagues who dance the original choreography. Additionally, a Leitmotif pose creates a thread throughout this section connecting the compositional material in various ways.

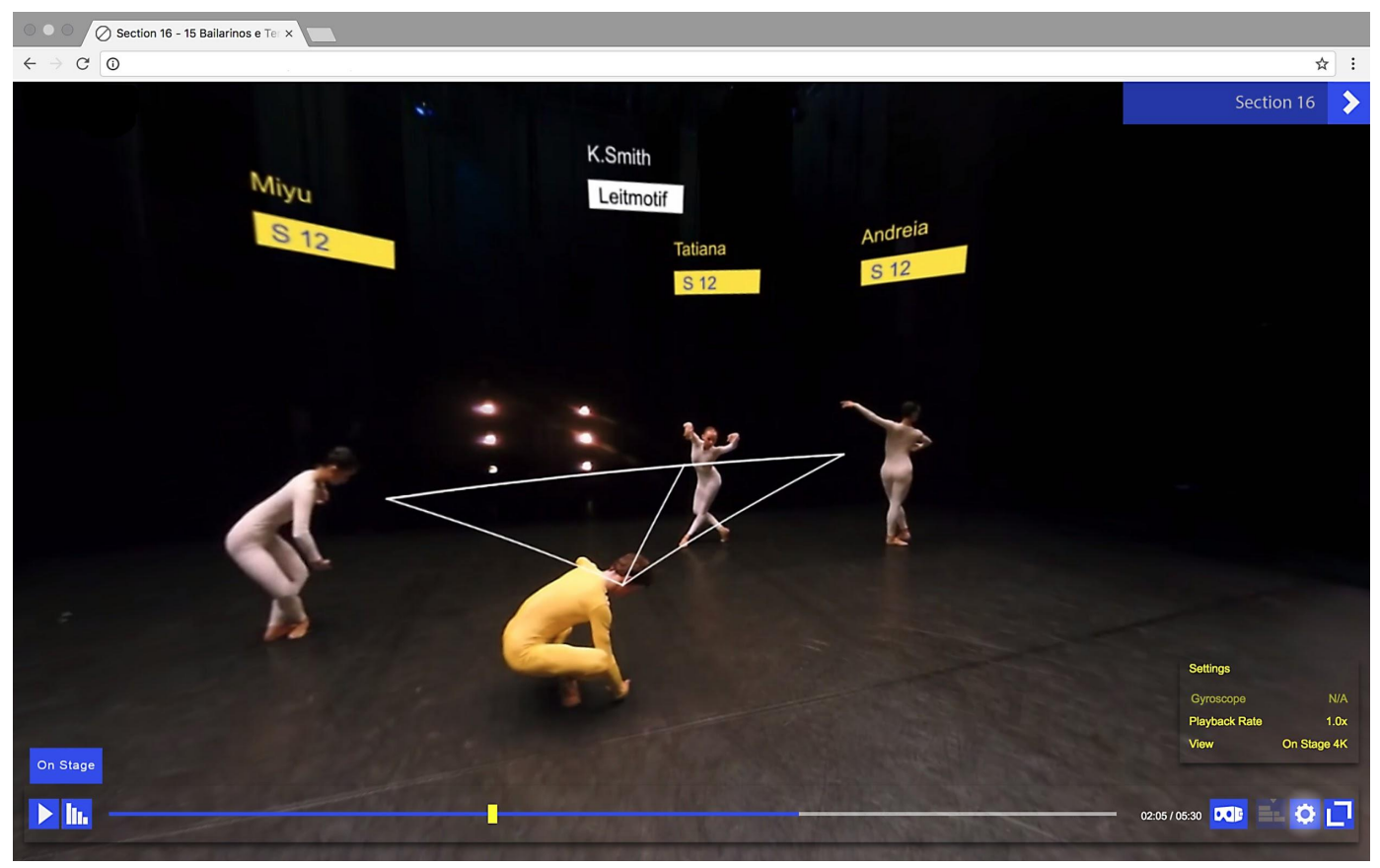

Figure 7. Screenshot of section sixteen in stage view mode.

Again, "audience view" and "stage view" modes offer complementary information. In audience view mode the Rewind section can be watched from the frontal perspective and the graphic score for this scene can be activated in the same way as described above. Switching to the stage view mode, the user can explore two types of information: the dancer's name is displayed in the space overhead, and a colored bar explains what choreographic material is presently performed.

On a second level of graphic information, those dancers who perform original or rewind material from the same section, are visually connected through thin horizontal white lines (see Figure 7). When a dancer proceeds to perform choreographic material from a different section, or exits the stage, these connecting lines are 
discontinued. In combination, the colored bars and connecting lines allow the user to simultaneously understand the compositional structure of the Rewind section and to watch the dance performance itself.

In conclusion, the multiple viewport platform for 360-degree dance video provides a variety of access points and modes of experience, all of which have their specific advantages and limitations. The more immersion the interface offers, the more intense and embodied the user experience tends to be, allowing the viewer to get a sense of the complexity involved in dancing this choreography on a large stage. On the other hand, compositional analysis requires an overview of the dramaturgical structures and interconnections. Hence we have designed an interface for the representation of these dance data sets, which corresponds to Wohlfart and Hauser's second (storytelling with interactive approval) and third (semi-interactive storytelling) modes of splitting control between the viewer and the authors. Additionally, 360-degree video provides specific visualization possibilities that conventional 2D video cannot offer: in the space above and below the dancers, infographic information could be placed. In this ideal scenario, the viewer can follow the dance without distractions and eventually consult the infographics to deepen their compositional and dramaturgical understanding of the dance they are witnessing.

\section{The Infographic Approach as an Act of Media-Practice-as-Research}

From an epistemological perspective, our platform presented above can be adequately described as a choreographic object, which disseminates academic findings about Penalva and Graça's conceptual and choreographic thinking in a novel and exploratory visualization format, designed by a media artist. However, this interpretation would not do justice to the complexity of the choreographic object: the user is not (simply) presented with the audio-visual "documentation" of the ballet and offered additional explanation about the underlying compositional principles and strategies. From this perspective, the platform is not intended to preserve ephemeral cultural heritage for posterity. Instead, our platform (like other choreographic objects) shares research on research in a methodological framework, which itself instigates further research (rather than presenting final conclusions). In other words, the dance itself can be seen as the (artistic) research data that Penalva and Graça produced when asking their (artistic) research question "How can we challenge the audience's tendency to look for a narrative in a ballet, and offer an alternative mode of experiencing our work?" In consequence, our platform presents research on these artists' research, asking 
"What compositional methods were employed to experience this non-narrative ballet? How can selected samples of dance data sets be processed, coded and visualized so that the compositional methods become visible?" Hence, the user of the platform does not experience the dance itself, but will find that his or her "encounters are performative of the research." ${ }^{\prime 37}$ It will be exciting to study in the future what kind of memories will be constructed of these encounters with infographic dance films and larger choreographic objects, such as the 360-degree platform presented above.

\section{Concluding Thoughts - Part One}

Recent research in embodied cognition theory applied to cinema suggests that an audience's understanding of visual meaning and abstract concepts in a film are closely related to the artistic use of "image schemes." Drawing on seminal works of cognitive linguists George Lakoff and Mark Johnson, cognitive film theorists Coëgnarts and Varanja present case studies on two filmmaker's (conscious or unconscious) use of image schemas to convey visual meaning and abstract concepts. ${ }^{38}$ Coëgnarts and Varanja refer to the idea of images schemes as proposed by Johnson:

An image schema is a recurring, dynamic pattern of our perceptual interactions and motor programs that gives coherence and structure to our experience. (...) Experience is to be understood in a very rich, broad sense as including basic perceptual, motor-program, emotional, historical, social and linguistic dimensions. ${ }^{39}$

Utilizing the containment image schema for detailed analysis of two well known film scenes from Citizen Kane and The Searchers, Coëgnarts and Varanja demonstrate how the viewer can access visual meaning through an embodied understanding of the compositional techniques employed by the filmmaker (inside versus outside settings, spatial organization and relations between the characters, choice of shot size and framing the image, etc.).

Put differently, the filmmaker builds on image schemas, which exist in the viewer's real-life experience. According to Coëgnarts and Varanja, the image schema

\section{of containment:}

(...) is regarded to play a crucial role in our understanding of abstract concepts. The notion of physical containment is grounded in a wide range of common basic experiences. For example, we experience our own bodies as threedimensional containers into which we put certain things (food and water) and out of which other things appear. We walk through doors into rooms. We move in vehicles, clothes and various other bounded regions in space. We put things into and out of containers and so forth (Johnson The Body 21). ${ }^{40}$ 
Transferring Coëgnarts and Varanja's train of thought to our discussion of the infographic films about the work of choreographers João Fiadeiro and Rui Lopes Graça, there are numerous compelling parallels. In our first case study on Fiadeiro's work, the containment image scheme is perspicuously present in our infographic film on Fiadeiro's graphic models: we have digitally re-created his "studio space," which the viewer can "enter" from a first-person perspective. Hence the "studio space" serves as both a metaphor of Fiadeiro's artistic universe, and a virtual (digitally re-created) "place," which exists in real life, the Atelier Re.al in Lissabon, Portugal.

Fiadeiro's stage work O Que Fazer Daqui Para Trás can be equally analyzed from the conceptual lens of the containment image scheme. To start with, any conventional theatre venue is split into a "stage" space and an "auditorium" space with distinct characteristics, functions and a set of associated behavioral rules. Fiadeiro and his dancers' performed actions can be understood entirely by the audience from the perspective of the embodied experience of the containment image scheme: entering the stage running, stopping and gasping for breath, trying to talk about something they just experienced a moment ago, exiting the stage running again. And yet, the audience experiences a disturbing tension between the immediate and total recognition of the performers' actions and the unexpected context of the actions: why do they dancers continuously run, enter, report, exit, and do so for the entire piece? Why is this a labelled a contemporary dance work? What is the meaning of the work? In fact, most of meaning-making process (on both sides, the artists' and audiences') manifests as the abstract concepts become embodied on stage. Absence and presence, for example, is one of Fiadeiro's key concepts. In a public conversation with Fiadeiro following the Oporto performance of the work in 2016, an audience member shared that she felt the dancers brought bits and pieces from the pulsating real life from the outside of the theatre onto the stage, a life she felt was often missing inside the theatre and in the productions habitually presented. Her shared experience is a fine example of how the artistic and creative use of a containment image schema by Fiadeiro triggered several very abstract reflections in this particular audience member.

However, there are less conspicuous examples of the containment image scheme to be found in the verbal dimensions of the work: the five dimensions of the discourses delivered by the dancers contain one another, starting with the body, expanding towards the audience, the city hosting the performance and eventually into more abstract political and philosophical dimensions of life. Figure 3 displays an animated disk model from our documentary film, based on a drawing which João 
Fiadeiro used to organize and develop the discourses in collaboration with the dancers. This animated disk model then transforms into the score shown in figure 4, which uses a color code for each discourse dimension and displays the order of entrances and exits along with the type of discourse delivered by each dancer. Here, the infographic visualization is helpful in understanding the crossmodal characteristic of the image scheme: the dancers do not only enter and exit the physical space of the stage but simultaneously enter and exit their respective discourse dimensions.

As we have seen, image schema such as the containment scheme are of great importance for the embodied filmmaking approach, which we have adopted for the creation of our infographic films. The role of the infographic narrative in communicating our research on the artists' research and creation processes has been to instigate professionals and interested non-specialists to engage with live dance works and choreographic objects through trusting their embodied perception in the process of meaning-making of the work they have experienced.

\section{Concluding Thoughts - Part Two}

Does the use of embodied filmmaking techniques have an impact on our research designs and choice of research methodologies? And, coming full circle, what do we consider to be relevant dance data sets for our BlackBox case studies? Along with visual theorist and artist Johanna Drucker, we think that it is paramount to rethink the term "data":

To overturn the assumptions that structure conventions acquired from other domains requires that we re-examine the intellectual foundations of digital humanities, putting techniques of graphical display on a foundation that is humanistic at its base. This requires first and foremost that we reconceive all data as capta. Differences in the etymological roots of the terms data and capta make the distinction between constructivist and realist approaches clear. Capta is "taken" actively while data is assumed to be a "given" able to be recorded and observed. From this distinction, a world of differences arises. (...) what is needed is not a set of applications to display humanities "data," but a new approach that uses humanities principles to constitute capta and its display. ${ }^{41}$

Drucker's conception of data as capta marks a decisive difference for all stages of the research process. Dance data are most frequently obtained in specific and unique collaborations and circumstances, which cannot be dissociated from another (but tend to be omitted from visualizations in the quest to present "given" data sets "objectively"). Moreover, the task of disambiguation of the dance data sets during the analytical process may be difficult, either, because the polysemic nature of dance is not 
recognized, or because there is a lack of embodied understanding of the observed phenomenon on the part of the researchers. Hence the presentation of processed and analyzed dance data (dance capta) ideally takes on a form, which grants access both to the choreographer's artistic process, and the scientist's research process.

We argue that the infographic information in combination with the presentation of accurately collected and selected dance data sets can constitute the kind of new approach Drucker is calling for. In other words, the infographic narrative does not present "given" data, facts and conclusions, but instead invites the viewer to partake in an often self-reflective dialogue between artists, dance works and researchers involvement. What's more, the creation of infographic films implies a recursive function for both, artists and researchers: frequently information and knowledge surfaces in the process of constructing the narrative, which instigates researchers and eventually artists to reflect about their work from a different and often unexpected, novel viewpoint. Future research will, therefore, take us to even deeper explore the specificities of digital media formats and techniques with regard to their potential as media-practice-as-research tools.

\section{Endnotes}

${ }^{1}$ See http://blackbox.fcsh.unl.pt/, accessed January 22, 2019.

2 Scott deLahunta, "Dance Becoming Data: Part One Software for Dancers," Computational Culture, Issue 6 (2017). Available from: $\mathrm{http}: / /$ computationalculture.net/dance-becoming-data-part-one-software-fordancers/, accessed January 22, 2019.

${ }^{3}$ See http://scores.motionbank.org/, accessed January 22, 2019.

${ }^{4}$ See https://synchronousobjects.osu.edu/, accessed January 22, 2019.

${ }^{5}$ Nora Zuniga Shaw, William Forsythe and Maria Palazzi. "The Dance, The Data, The Objects." Synchronous Objects. The Ohio State University, (2009). Available from: https://synchronousobjects.osu.edu/assets/objects/introduction/danceDataObjectE ssays.pdf, accessed January 22, 2019.

${ }^{6}$ See https://www.siobhandaviesreplay.com/, accessed January 22, 2019.

${ }^{7}$ Sarah Whatley, "Accidental Archives of Performance Making." Proceedings from the Document Academy, (in press) (2018).

${ }^{8}$ For the TKB project see: http://tkb.fcsh.unl.pt/ and for the BlackBox project consult: http://blackbox.fcsh.unl.pt/, accessed January 22, 2019.

${ }^{9}$ See http://tkb.fcsh.unl.pt/content/knowledge-base-performing-arts, accessed January 22, 2019. 
10 Stephan Jürgens and Carla Fernandes "Choreographic practice-as-research Visualizing conceptual structures in contemporary dance." In: Performance as Research: Knowledge, Methods, Impact, eds. Annette Arlander, Bruce Barton, Melanie Dreyer-Lude and Ben Spatz (London and New York: Routledge, 2017), 249-274.

${ }^{11}$ Kwan-Liu Ma, Isaac Liao, Jennifer Frazier, Helwig Hauser, and Helen-Nicole Kostis. "Scientific storytelling using visualization." Computer Graphics and Applications, IEEE, 32(1) (2012):12-19,.

12 Stephan Jürgens and Carla Fernandes "Visualizing Embodied Research: Dance Dramaturgy and Animated Infographic Films." Journal of Embodied Research 1.1 London and New York: Routledge, video article (27:41), 2018. Available from: http://doi.org/10.16995/jer.4, accessed January 22, 2019.

13 See note 11, 18. "Traditional passive storytelling prohibits interaction on the consumer's part; the author fully controls all domains. In storytelling with interactive approval, passive storytelling pauses at certain points and lets spectactors take temporary control. They can change the visualization's view, representation, and even content. Once they're satisfied with this interactive exploration, storytelling continues as originally intended. In semi-interactive storytelling, consumers can take control not just for an interim excursion but for an entire section of the story. Finally, in total separation from the story, consumers can completely detach from the story and engage in interactive visualization with total freedom."

${ }^{14}$ Stephan Jürgens, Francisco Henriques and Carla Fernandes "Re-constructing the Choreographic Studio of João Fiadeiro through Animated Infographic Films," PARtake: The Journal of Performance as Research, 1.1. (2016). Available from: scholar.colorado.edu/partake/vol1/iss 1/3/, accessed January 22, 2019.

${ }^{15}$ See note 14,8 .

${ }^{16}$ Film available from: https://vimeo.com/149281774, accessed January 22, 2019.

${ }^{17}$ See http://blackbox.fcsh.unl.pt/joao-fiadeiro-solos-enactments-study.html, accessed January 22, 2019.

${ }^{18}$ See note 13.

${ }^{19}$ Researchers may opt to work with data which they have collected first-hand, or primary data, which refers to data under the form of video recordings, surveys, interviews, field notes, and so forth. Ideally this data is collected keeping the research question and the research design in mind in order to best capture information regarding the epistemic object under scrutiny. Alternatively, researchers may choose or be forced to use secondary data, that is, data collected by others, which has the advantage of being more economic in terms of time and other resources. It should be noted that "secondary" does not refer to the degree of importance of the data, but to the fact that it is second-hand data, information gathered and documented by someone else.

${ }^{20}$ In the very beginning of the film the viewer is advised: "This documentary has been produced using footage from the rehearsal period and public performances of $O$ Que Fazer Daqui Para Trás between July 2015 and October 2016. Originally, the video footage was recorded with the sole purpose of documenting the compositional process for scientific research in the framework of the BlackBox 
project. During the research process we realized that the footage should be shared with the general public. What you will see now, is not a conventional documentary, but an invitation to accompany the collaborative creative process of João Fiadeiro and five performers."

The documentary is available from: http://blackbox.fcsh.unl.pt/joao-fiadeiro-what-todo-with-what-remains.html, accessed January 22, 2019.

${ }^{21}$ For a detailed discussion of the work see: Stephan Jürgens, "How to Communicate on the Verge of Collapse," Choreographic Practices, 8: 1 (2017): 89-109, https://doi.org/10.1386/chor.8.1.89_1.

${ }^{22}$ Compare note 12.

${ }^{23}$ See reference in note 10 on this topic.

${ }^{24}$ Compare https://www.techopedia.com/definition/6597/computing, accessed January $22,2019$.

25 Angus Graeme Forbes, "Articulating Media Arts Activities in Art-Science Contexts," Leonardo 48, No. 4, (2015): 330-337.

${ }^{26}$ Sarah Whatley, "Transmitting, Transforming and Documenting Dance in the Digital Environment - What Dance Does Now that It Didn't Do Before," TDR: The Drama Review 61:4, (2017):78-95.

${ }^{27}$ Ibid.

${ }^{28}$ The Nutcracker in 360 degrees

https://www.youtube.com/watch? $\mathrm{v}=$ yo2keosacZY\&t=211s, accessed January 22, 2019.

29 Giselle VR https://www.facebook.com/SkyArtsHD/videos/10154470724381153/, accessed January 22, 2019.

${ }^{30}$ Night Fall https://www.youtube.com/watch?v=xCp4at6LE0A and Silent Resonance https://www.youtube.com/watch?v=TStaOhkFrPY, accessed January 22, 2019.

${ }^{31}$ Compare references in notes 4 and 6.

32 Capturing Intention.

$\mathrm{http}$ ://insidemovementknowledge.net/context/background/capturing-intention, accessed January 22, 2019.

${ }^{33}$ Compare references in notes 12 and 14.

34 Jaqueline Chu, Chris Bryan, Min Shih, Leonardo Ferrer and Kwan-Liu Ma "Navigable Videos for Presenting Scientific Data on Head-Mounted Displays," MMSys'17 Proceedings of the 8th ACM on Multimedia Systems Conference (New York: ACM), (2017):250-260.

${ }^{35}$ Compare notes 11 and 13.

36 To enter the platform, go to: http://blackbox.fcsh.unl.pt/media.html, accessed January 22, 2019.

${ }^{37}$ For more information on this methodology developed in the framework of the BlackBox Project, see reference in note 10. 
${ }^{38}$ Maarten Coegnarts and Peter Kravanja "Embodied Cognition and Cinema." In Embodied Cognition and Cinema. eds. Maarten Coegnarts and Peter Kravanja (Leuven: Leuven University Press, 2015), 63-80.

39 Ibid., 70.

${ }^{40}$ Ibid.

41 Johanna Drucker "Humanities Approaches to Graphical Display," Digital Humanities Quarterly (2011). Available from. https://pdfs.semanticscholar.org/e0fe/227ff7a3822f5c0bd41cc566fla472cc22f2.p df, accessed January 22, 2019. 